\title{
Sensitivity to Envelope Interaural Time Difference: Models of Diverse LSO Neurons
}

\author{
Andrew Brughera*1,2 ${ }^{\text {, Jimena A. Ballestero }}{ }^{3}, \&$ David McAlpine ${ }^{1}$ \\ ${ }^{1}$ Department of Linguistics, and the Australian Hearing Hub, Macquarie University, \\ Macquarie Park, New South Wales, Australia \\ 2 Department of Biomedical Engineering, Boston University, \\ Boston, Massachusetts, United States of America \\ 3 Instituto de Fisiología y Biofísica (IFIBIO) Bernardo Houssay, Grupo de Neurociencia de \\ Sistemas, Universidad de Buenos Aires, CONICET, Buenos Aires, Argentina \\ * Corresponding author: Andrew Brughera: andrew.brughera@mq.edu.au
}

ORCiD information:

Andrew Brughera: https://orcid.org/0000-0002-2461-3894

Jimena A. Ballestero: https://orcid.org/0000-0002-7846-7845

David McAlpine: https://orcid.org/0000-0001-5467-6725

\begin{abstract}
: 184 words
Introduction: 663 words

Discussion: 1658 words

Number of tables: 2

Number of figures: 5
\end{abstract}

\begin{abstract}
A potential auditory spatial cue, the envelope interaural time difference (ITD ENV) is encoded in the lateral superior olive (LSO) of the brainstem. Here, we explore computationally modeled LSO neurons, in reflecting behavioral sensitivity to ITD ENv. Transposed tones (half-wave rectified low-frequency tones, frequency-limited, then multiplying a high-frequency carrier) stimulate a bilateral auditory-periphery model driving each model LSO neuron, where electrical membrane impedance low-pass filters the inputs driven by amplitude-modulated sound, limiting the upper modulation rate for ITD ENV sensitivity. Just-noticeable differences in ITD ENV for model LSO neuronal populations, each distinct to reflect the LSO range in membrane frequency response, collectively reproduce the largest variation in ITD ENV sensitivity across human listeners. At each stimulus carrier frequency $(4-10 \mathrm{kHz})$ and modulation rate $(32-800 \mathrm{~Hz})$, the top-performing model population generally reflects top-range human performance. Model neurons of each speed are the top performers for a particular range of modulation rate. Offfrequency listening extends model ITD ENV sensitivity above $500-\mathrm{Hz}$ modulation, as sensitivity decreases with increasing modulation rate. With increasing carrier frequency, the combination of decreased top membrane speed and decreased number of model neurons capture decreasing human sensitivity to ITD ENV.
\end{abstract}

Keywords: binaural, envelope ITD, lateral superior olive, sensory coding, spatial hearing, transposed tone 


\section{Declarations}

\section{Funding}

This work was supported by Australian Research Council Laureate Fellowship (FL160100108) awarded to DM.

\section{Conflicts of interest/Competing interests}

The authors declare that they have no conflict of interest, and no competing interest.

\section{Ethics approval}

For this strictly computational study, no approval was required.

\section{Consent to participate}

For this strictly computational study, no consent was required.

\section{Consent for publication}

For this strictly computational study, there are no human subjects from whom consent is required. All authors and responsible authorities approve the publication of this manuscript.

\section{Availability of data and material}

Data and analysis scripts: https://doi.org/10.6084/m9.figshare.12798035.v1

\section{Code Availability}

Code: https://github.com/AndrewBrughera/LSO Transposed Tones

\section{Author Contributions}

Conceptualization: DM

Data Curation: $A B$

Formal Analysis: $A B$

Funding Acquisition: DM

Investigation: $A B$

Methodology: $A B$

Project administration: AB, JB, DM

Resources: $D M, A B$

Software: $A B$

Supervision: $\mathrm{DM}$ and $\mathrm{JB}$

Visualization: $A B$

Validation: $A B$

Writing - Original Draft Preparation: $A B$

Writing - Review \& Editing: $A B, D M, J B$ 


\section{Introduction}

Human listeners exploit differences in the intensity and timing of sounds arriving at the two ears-interaural intensity differences (IIDs) and interaural time differences (ITDs), respectively - to determine the location of the source on the horizontal plane (Blauert, 1997). For sound frequencies below about $1400 \mathrm{~Hz}$, human IIDs are small except for sources very close to the head (Brungart \& Rabinowitz, 1999), and source location is determined primarily from ITDs conveyed in the temporal fine structure (TFS, ITD TFS) of sounds (Wightman \& Kistler, 1992). At higher sound frequencies, listeners exploit IIDs for source localization (Mills, 1960; Sandel et al., 1955) and, under laboratory conditions at least, are sensitive to ITDs conveyed in the modulated envelope of sound pressure, referred to as "envelope ITD" (ITD ENV) (McFadden \& Pasanen, 1976). Human abilities to exploit ITD ENV under natural listening conditions remains an open question, which is particularly relevant to listeners with bilateral cochlear implants (bCls, $\mathrm{Cls}$ ): as clinical $\mathrm{Cl}$ processors convey only the correct envelope, and not the correct TFS (Gransier et al., 2020).

Sensitivity to binaural spatial cues relies on neural encoding in the medial and lateral superior olive (MSO and LSO, respectively) of the auditory brainstem. MSO neurons, innervated with

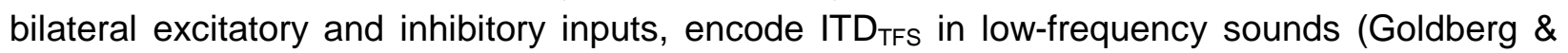
Brown, 1968, 1969; Grothe \& Sanes, 1993; Yin \& Chan, 1990), by mechanisms of fast binauralcoincidence detection temporally sharpened by low-threshold potassium ( $\left.\mathrm{K}_{\mathrm{LT}}\right)$ channels (Mathews et al., 2010). LSO neurons, innervated by ipsilateral excitatory and contralateral inhibitory inputs (Fig. 1A), encode IID (Boudreau \& Tsuchitani, 1967) and ITD ENv conveyed in high-frequency sounds (Batra et al., 1997; Joris, 1996; Joris \& Yin, 1995, 1998). Some LSO neurons express $\mathrm{K}_{\mathrm{LT}}$ channels in rapidly-responding membranes, while others, increasingly common in higher-frequency regions of the LSO, have more slowly-responding integrative membranes, consistent with the encoding of IID (Barnes-Davies et al., 2004; Remme et al., 2014).

Psychoacoustic studies show smaller just-noticeable differences (JNDs) in the ITD frequency tones (Brughera et al., 2013), compared with larger JNDs in the ITD ENV of modulated high-frequency tones (Bernstein \& Trahiotis, 2002, 2014; Monaghan et al., 2015). These studies demonstrate two additional features specific to ITD ENV. First, sensitivity to ITD ENV is extremely variable across listeners, including listeners highly trained in ITD ENV discrimination, and

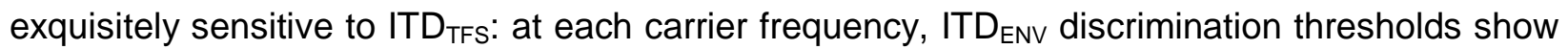
four-to-ten-fold differences for the same modulation rate, and two-to-five-fold differences in the highest modulation rate with a measurable threshold. Second, with increasing carrier frequency, there is a decrease in ITD ENV sensitivity, and in the maximum modulation rate with a measurable threshold. This worsening performance is paradoxical, as cochlear filters broaden in absolute bandwidth with increasing sound frequency (Glasberg \& Moore, 1990), thereby better passing the modulation sidebands of amplitude-modulated sounds. This paradoxical decrease in ITD ENV sensitivity with increasing carrier frequency, and the variance in ITD ENV sensitivity across human listeners, remain unexplained.

Here, we explore computationally modeled LSO neurons, in reflecting behavioral sensitivity to ITD ENV. We extend a Hodgkin-Huxley-type model LSO neuron (Wang \& Colburn, 2012) to populations, each distinct to reflect the range of membrane frequency responses observed in the LSO (Remme et al., 2014), with a membrane time constant from slow to very fast. Bilaterally innervating each model LSO neuron (Fig. 1B), an auditory-periphery model (Zilany et al., 2014) is stimulated by transposed tones (Fig. 2): high-frequency tones modulated with an envelope 
designed to evoke auditory temporal resolution reflecting TFS in low-frequency sounds (van de Par \& Kohlrausch, 1997). At each stimulus carrier frequency and modulation rate, the topperforming model population generally reflects the best human performance. Model neurons of each speed provide the best performance over a particular range of modulation rate. 'Offfrequency listening' extends ITD ENV sensitivity up to the modulation rates observed in the bestperforming human listeners. Decreasing $I T D_{E N V}$ sensitivity with increasing carrier frequency required reduced top model membrane speed and number of model neurons. The largest variation in sensitivity to ITD ENv across human listeners is captured by the heterogeneity in model membranes.

A

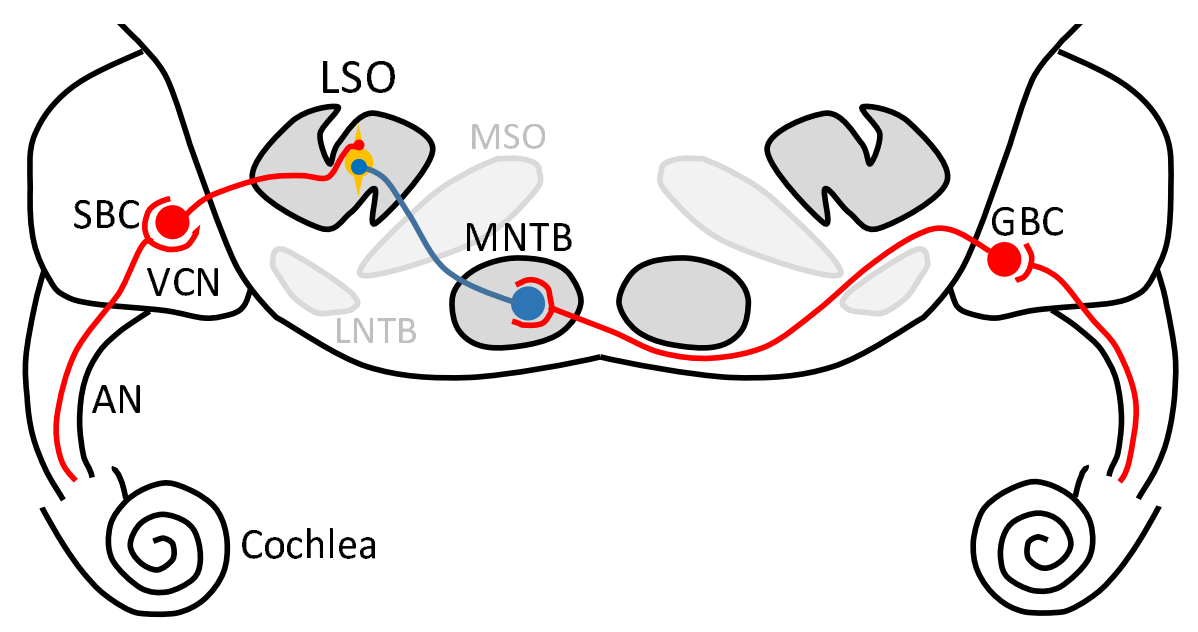

B Hodgkin-Huxley-type

\section{model LSO neuron}

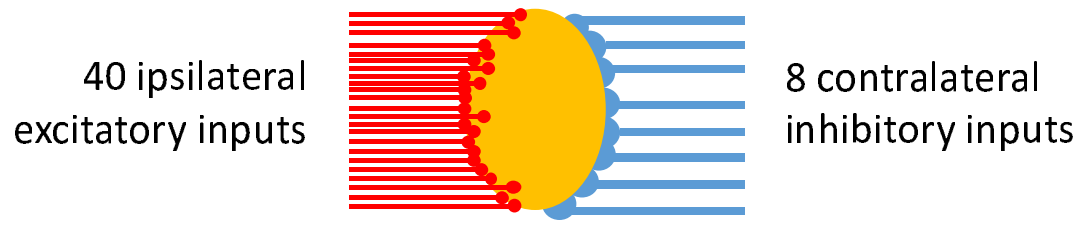

Fig. 1. A: Inputs to the lateral superior olive (LSO). Excitatory neurons, axons, and synapses are in red; inhibitory in blue. The LSO receives ipsilateral excitation from spherical bushy cells (SBCs) of the ventral cochlear nucleus (VCN), each driven by 1-3 auditory-nerve (AN) fibers (ANFs) (Doucet \& Ryugo, 2003; Lorente De No, 1981; Smith et al., 1993). The LSO receives contralateral inhibition from principal neurons of the medial nucleus of the trapezoid body (MNTB), each driven by a globular bushy cell (GBC) of the VCN; GBCs are driven by 9-70 ANFs (Banks \& Smith, 1992; Glendenning et al., 1985; Smith et al., 1991; Spirou et al., 2005). B: Model LSO neuron with a single $\mathrm{HH}$-type compartment, receiving simplified inputs directly from model ANFs: 40 ipsilateral excitatory inputs and 8 contralateral inhibitory inputs 

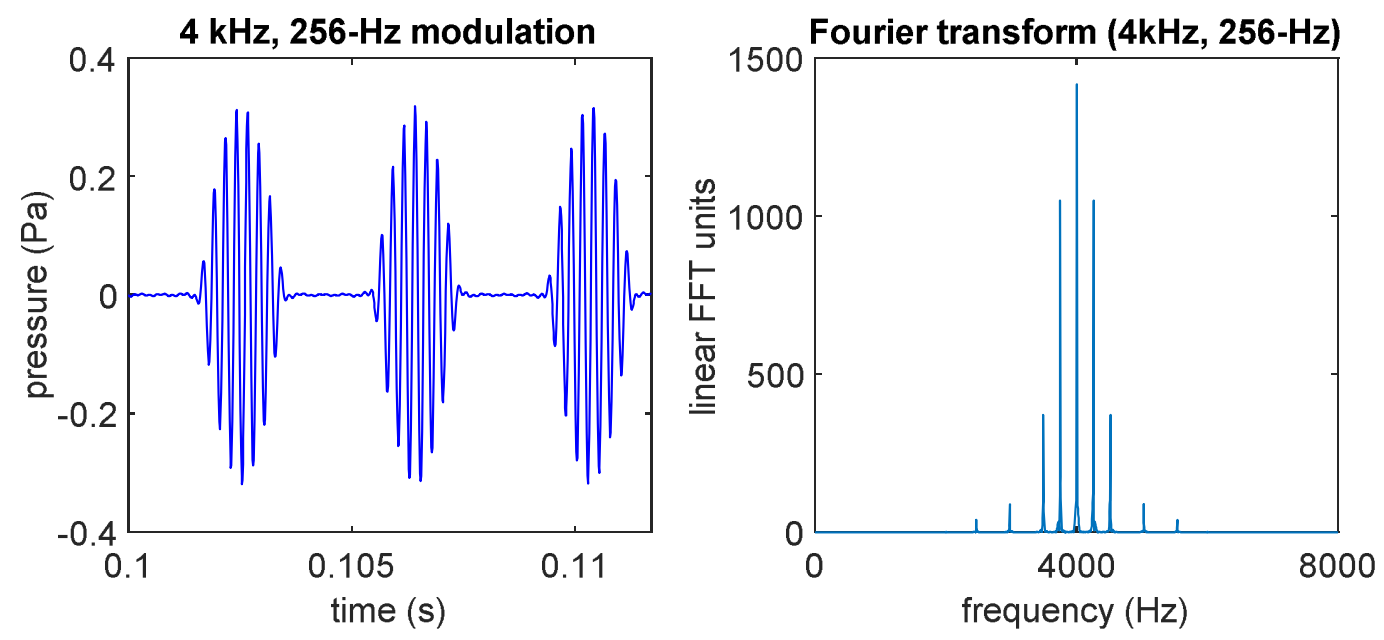

Fig. 2. Transposed tone: a half-wave rectified low-frequency sinusoid, frequency-limited, then multiplying a high-frequency sinusoid as the carrier. Left: A transposed tone with a $4-\mathrm{kHz}$ carrier, and modulation rate of $256 \mathrm{~Hz}$. The envelope signal (not shown) is a 256- $\mathrm{Hz}$ sinusoid, half-wave rectified, with frequency components above $2 \mathrm{kHz}$ then removed (leaving $0 \mathrm{~Hz}, 256$ $\mathrm{Hz}, 512,1024$, and $1536 \mathrm{~Hz}$, which includes even harmonics of $256 \mathrm{~Hz}$ ). Forming the transposed tone, this envelope signal multiplies a $4-\mathrm{kHz}$ sinusoidal carrier. Right: The fast Fourier transform of the transposed tone shows its frequency spectrum: a center peak at the 4$\mathrm{kHz}$ carrier frequency, and modulation sidebands from the envelope signal, above and below the carrier by $256 \mathrm{~Hz}$ and its even harmonics up to $1536 \mathrm{~Hz}$, with the extreme sidebands at 2464 and $5536 \mathrm{~Hz}$. The limited frequency range of the envelope insures that this transposed tone has no frequency component below $2 \mathrm{kHz}$

\section{Methods}

\section{Auditory Stimuli}

The auditory stimuli were transposed tones (Fig. 2) (Bernstein \& Trahiotis, 2002; van de Par \& Kohlrausch, 1997): low-frequency tones, half-wave rectified, then band limited to frequencies below $2000 \mathrm{~Hz}$, each multiplying a high-frequency carrier. Transposed-tone stimuli had maximum sound pressure level (SPL) 75 dB RMS, 300-ms duration, 20-ms cosine-squared ramps at onset and offset, carrier frequencies of 4,6 , and $10 \mathrm{kHz}$, and modulation rates of 32 , $64,128,256,512$, and $800 \mathrm{~Hz}$. Within each stimulus, phase of the carrier and envelope were steady. Across stimulus presentations, carrier phase was randomized, and the envelope phase (phase relative to the amplitude-modulation cycle) ranged from 0 to $-525^{\circ}$ in increments of $15^{\circ}$ (negative phase is delay).

\section{Auditory-Periphery Model}

Twenty-five repetitions of each transposed tone were applied bilaterally to an auditory-periphery model for humans (Glasberg \& Moore, 1990; Zilany et al., 2014). With these stimulus repetitions, the stochastic auditory-periphery model provided 25 independent sets of spike times at each of the 36 envelope phases, for each of 40 model auditory-nerve (AN) fibers (ANFs) acting as excitatory synaptic inputs, and 8 model ANFs acting as inhibitory synaptic inputs, to the model LSO neurons (Fig. 1). Numbers of inputs are based on a recent model from anatomical counts (Gjoni et al., 2018). On-frequency listening conditions were implemented with ANFs having characteristic frequency (CF, the frequency of lowest spike-threshold in SPL) equal to the stimulus carrier frequency. Off-frequency listening conditions were implemented with ANFs having a single CF between the carrier frequency of the stimulus, and its first upper 
modulation sideband. Off-frequency listening in moderate, fast and very fast model LSO neurons separately applied ANFs with CF equal to 4.28, 4.43. 6.28, 6.43, 10.28, 10.43, or 10.56 $\mathrm{kHz}$; HL-quick model neurons (named for their high conductances for $h$ channels and leakage channels, and quick model membrane reflecting fast non-resonant LSO neurons) applied ANFs with CF equal to $4.28,6.28$, or $10.28 \mathrm{kHz}$. Model results for off-frequency listening are shown for CF equal to only $4.28,6.28$, and $10.28 \mathrm{kHz}$, providing a fair comparison with on-frequency listening. Simplified inputs to the model LSO (Fig. 1B) maintain the ipsilateral excitation and contralateral inhibition of the LSO, with the cochlear nuclei and trapezoid body modeled as relays without delay.

\section{Model LSO Neurons}

Model LSO neurons were implemented using the Brian 2 Neural Simulator (Stimberg et al., 2019) in Anaconda Python 3.7 64-bit http://www.anaconda.com .

Code is available: https://github.com/AndrewBrughera/LSO Transposed Tones

Data and analysis scripts: https://doi.org/10.6084/m9.figshare.12798035.v1

IPD $D_{E N V}$, the interaural phase difference with respect to the amplitude modulation cycle of the transposed-tone was fixed within each simulation, and ranged from -180 to $+180^{\circ}$ in increments of $15^{\circ}$. At each IPD $D_{E N V}$, a different one of 24 envelope starting phase pairs was applied for each model LSO neuron within a population of 10 or 24 neurons. The 25 stimulus repetitions, each yielding spike times from the model ANFs, were each applied separately. Across the six populations of model LSO neurons, the same sets of input spike times were applied, except that for the slow model LSO neurons, a 1-ms delay was added to the spike-times driving

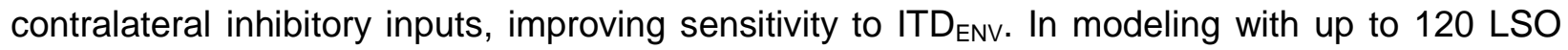
neurons per carrier frequency, we considered the 5600 neurons each in the left and right LSO (Kulesza, 2007), in just under 10 octaves of frequency range in human hearing from 20 to $20,000 \mathrm{~Hz}$, yielding 140 neurons in each LSO per quarter-octave in equal log-spacing, without a bias toward high-frequency neurons.

Modeling LSO neurons, we extend an existing Hodgkin-Huxley-type model LSO neuron (Hodgkin \& Huxley, 1952; Rothman \& Manis, 2003; Wang \& Colburn, 2012) to six populations: slow, moderate, HL-quick, brisk, fast, and very fast. All model LSO neurons have membrane conductances (Table 1) and reversal potentials, representing leakage (L) channels, sodium $\left(\mathrm{Na}^{+}\right)$channels, high-threshold potassium $\left(\mathrm{K}_{\mathrm{HT}}\right)$ channels, and hyperpolarization-activated cyclic nucleotide (h) channels for non-specific cations (reversal potentials: $V_{L}=-65 \mathrm{mV} ; V_{N a}=+55 \mathrm{mV}$; $V_{K}=-70 \mathrm{mV} ; V_{H}=-43 \mathrm{mV}$ ). Brisk, fast, and very fast model neurons also include a conductance (Table 1) and reversal potential for $\mathrm{K}_{\mathrm{LT}}$ channels $\left(V_{K}=-70 \mathrm{mV}\right)$. Slow model neurons use a model membrane for VCN stellate cells (Type 1c) (Rothman \& Manis, 2003); moderate model neurons have increased conductances for $\mathrm{h}$ channels and leakage channels; and HL-quick model neurons have relatively high conductances for $\mathrm{Na}^{+}, \mathrm{K}_{\mathrm{HT}}$, $\mathrm{h}$ and leakage channels. Fast model neurons use a model membrane for VCN bushy cells (Type 2) (Rothman \& Manis, 2003), previously applied to LSO modeling (Wang \& Colburn, 2012). The brisk model LSO neuron has half the $\mathrm{K}_{\mathrm{LT}}$ and $\mathrm{h}$ conductances of the fast model neuron. The very fast model LSO neuron has double the $\mathrm{Na}^{+}, \mathrm{K}_{\mathrm{HT}}, \mathrm{K}_{\mathrm{LT}}$, and $\mathrm{h}$ conductances of the fast model neuron. Maximum conductance values (Table 1) were not adjusted for temperature. Voltage-sensitive gate activation and inactivation equations for ion channels $\left(\mathrm{Na}^{+}, \mathrm{K}_{\mathrm{HT}}, \mathrm{K}_{\mathrm{LT}}, \mathrm{h}\right)$ are identical to those in Rothman and Manis (2003c) including time constants divided by the $Q_{10}$ temperature factor of $3^{(T-22) / 10} ; T$ is equal to human body temperature, $37^{\circ} \mathrm{C}$. Consistent across model neurons are the threshold for counting action potentials $\left(V_{A P-T H R E S H O L D}=-30 \mathrm{mV}\right)$, and the reversal potentials of excitatory 
synapses $\left(V_{E}=0 \mathrm{mV}\right)$ and inhibitory synapses $\left(V_{l}=-90 \mathrm{mV}\right)$. In faster model neurons, synapses are made faster and stronger, as inhibitory synapses maintain 10 times the strength, and 2 times the duration, of excitatory synapses (Table 1). An input spike from a model ANF to an excitatory synapse increments, by the excitatory synaptic strength $\Delta g_{E}$, the total inhibitory synaptic conductance $\left(g_{E}\right)$ which decays exponentially with time constant $\tau_{E}$ while producing excitatory synaptic current $i_{E}=g_{E}\left(V_{E}-V_{M}\right)$, where $v_{M}$ is the membrane potential. Similarly, an input spike from a model ANF to an inhibitory synapse increments, by the inhibitory synaptic strength $\Delta g_{l}$, the total inhibitory synaptic conductance $\left(g_{l}\right)$ which decays exponentially with time constant $\tau_{l}$ while producing inhibitory synaptic current $i_{l}=g_{l}\left(V_{l}-v_{M}\right)$, with the reversal potential $V_{l}$ below resting potential $\left(V_{R E S T}\right)$ to send current out of the model neuron.

Table 1. Parameters varying across model LSO neurons: maximum conductances $\left(g_{\max }\right)$ for ion channels, membrane capacitance, synaptic strengths, and synaptic time constants

\begin{tabular}{|c|c|c|c|c|c|c|}
\hline \multirow[b]{2}{*}{$\begin{array}{l}\text { Ion-channel } \\
\text { conductances: }\end{array}$} & \multicolumn{6}{|c|}{ Model LSO neurons: } \\
\hline & Slow & Moderate & $\begin{array}{c}\text { HL- } \\
\text { Quick }\end{array}$ & Brisk & Fast & $\begin{array}{l}\text { Very } \\
\text { Fast }\end{array}$ \\
\hline$g_{\text {max }_{\mathrm{Na}}}$ & 1000 & 1000 & 2000 & 1000 & 1000 & 2000 \\
\hline $\mathbf{g}_{\max _{\mathrm{KHT}}}$ & 150 & 150 & 300 & 150 & 150 & 300 \\
\hline$g_{\max _{K L T}}$ & 0 & 0 & 0 & 100 & 200 & 400 \\
\hline$g_{\max _{h}}$ & 0.5 & 1.85 & 24 & 10 & 20 & 40 \\
\hline $\mathbf{g}_{\text {Leak }}$ & 2 & 7.4 & 24 & 2 & 2 & 2 \\
\hline $\begin{array}{l}\text { Membrane capacitance, } \\
\boldsymbol{C}_{\boldsymbol{M}}\end{array}$ & 12 & 21.7 & 12 & 12 & 12 & 12 \\
\hline \multicolumn{7}{|l|}{ Excitatory synapses: } \\
\hline Strength, $\Delta g_{E}(\mathrm{nS})$ & 0.7 & 4.5 & 5 & 3 & 5 & 10 \\
\hline Time Constant, $\tau_{E}(\mathrm{~ms})$ & 1.5 & 1.5 & 0.5 & 1 & 0.5 & 0.2 \\
\hline \multicolumn{7}{|l|}{ Inhibitory synapses: } \\
\hline Strength, $\Delta \boldsymbol{g}_{\boldsymbol{I}}(\mathrm{nS})$ & 7 & 45 & 50 & 30 & 50 & 100 \\
\hline Time Constant, $\tau_{l}(\mathrm{~ms})$ & 3 & 3 & 1 & 2 & 1 & 0.4 \\
\hline
\end{tabular}

\section{Membrane impedance as a function of frequency in model LSO neurons}

We calculated subthreshold membrane impedance as functions of frequency in each type of model LSO neuron (slow, moderate, HL-quick, brisk, fast, and very fast): based on the membrane potential resulting from an injected transmembrane current (izap), a "zap" stimulus containing a linear frequency sweep from 1 to $2000 \mathrm{~Hz}$, beginning at time $t=0$ in the equation below, with a duration $d$ of one second (Table 2) (Hutcheon \& Yarom, 2000; Puil et al., 1986; Remme et al., 2014).

$d=1 \mathrm{~second} ; f_{\max }=2000 \mathrm{~Hz} ; f_{\min }=1 \mathrm{~Hz} ; m_{200 o}=\left(f_{\max }-f_{\min }\right) / 2 d$

$i_{Z a p}=I_{B I A S}+I_{\text {ZapMax }} \sin \left(2 \pi\left(m_{20 o o} t+f_{\min }\right) t\right) \quad($ for $0 \leq t \leq 1)$ 
Table 2. Current and voltage during membrane impedance determination

\begin{tabular}{|l|c|c|c|c|c|c|}
\hline \multicolumn{2}{|l|}{ Model LSO neurons: } \\
\hline $\begin{array}{l}\text { Membrane voltages } \\
\text { and applied currents: }\end{array}$ & Slow & Moderate & HL-Quick & Brisk & Fast & $\begin{array}{l}\text { Very } \\
\text { Fast }\end{array}$ \\
\hline $\boldsymbol{V}_{\boldsymbol{R E S T}}(\mathrm{mV})$ & -63.9 & -64.1 & -62.5 & -63.7 & -63.6 & -63.6 \\
\hline $\boldsymbol{I}_{\boldsymbol{B I S}}(\mathrm{pA})$ & 9 & 36 & 100 & 100 & 150 & 300 \\
\hline $\boldsymbol{V}_{\boldsymbol{M}}(\mathrm{mV})$ with $\boldsymbol{I}_{\text {BIAS }}$ & -58.9 & -59.1 & -59.3 & -58.5 & -59.3 & -59.2 \\
\hline $\boldsymbol{I}_{\text {ZapMax }}(\mathrm{pA})$ & 3 & 1 & 3 & 60 & 60 & 60 \\
\hline
\end{tabular}

Prior to the "zap" stimulus, the model membrane settled for 50 ms to its resting potential near $64 \mathrm{mV}$. Then an inward bias current $\left(I_{B I A S}\right)$ was applied with magnitude such that $v_{M}$ increased to near -59 mV. This bias current was applied alone for $450 \mathrm{~ms}$, and then maintained as the "zap" frequency sweep in membrane current $\left(i_{Z A P}\right)$ was also applied. For the HL-quick model neuron, we also examined the effect of reduced duration in bias current before $i_{\text {ZAP. }}$. Membrane impedance as a function of frequency was calculated using the fast Fourier transform (FFT). FFTs of the injected transmembrane current, and the resulting membrane voltage, were computed over the duration of the frequency sweep. The FFT of voltage was divided by the FFT of current, yielding the FFT of membrane impedance. The magnitude of this FFT was plotted, showing the magnitude of membrane impedance as a function of frequency.

\section{Neural Just-Noticeable Differences (JNDs) in Interaural Time Difference (ITD)}

We calculated neural JNDs from Fisher information in the spike rates of our model LSO neurons (shown in Figs. 3 and 4) analyzed as functions of ITD ENv. For each of 25 stimulus presentations of a 300-ms transposed tone, we calculated a JND in ITD ENV for each population of 24 model LSO neurons, based on a method of neuronal JND(IID) calculation (Brown \& Tollin, 2016), which we extended to a neuronal population:

$$
\begin{aligned}
& J N D(I T D)=1 / \sqrt{\text { FI(ITD) }} \quad(\text { Fl: Fisher information }) \\
& J N D(\text { ITD })=\frac{\left[\frac{\sigma_{\text {SpikeRate }}(\text { ITD })}{(\sqrt{N})}\right]}{\left[\frac{d(\text { SpikeRate })}{d(\text { ITD })}\right]}
\end{aligned}
$$

The arithmetic standard deviation in spike rate, $\sigma_{\text {SpikeRate, }}$ was calculated over the $N$ (24 or 10) model neurons in the population. Thus the bracketed numerator is the standard error of the mean spike rate for this population, calculated as the root-mean-square of the standard errors of mean spike rate at $I P D_{E N V}$ equal to $-45^{\circ}$ and $0^{\circ}$. The bracketed denominator is the derivative of mean spike rate with respect to ITD $D_{\mathrm{ENV}}$, calculated as a linear slope over the interval of ITD $_{\mathrm{ENV}}$

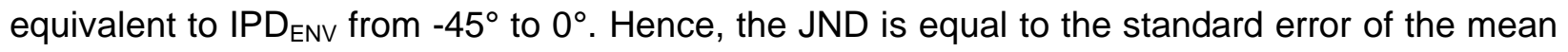
spike rate, divided by the derivative of mean spike rate with respect to ITD ENv. Agreement in the algebraic sign of the derivative in at least 19 of the 25 stimulus repetitions is the criterion for valid JND statistics in each stimulus condition. If this criterion was not met, the JND was considered to be unmeasurably high (the task was impossible). If this criterion was met, the geometric mean and standard deviation of JND were then calculated from the absolute values 
of all finite values of JND from the 25 stimulus repetitions. Typically all 25 of 25 JND values were finite, and the minimum was 23 of 25.

\section{Results}

Membrane impedances and frequency responses of model neuronal membranes

We calculated subthreshold membrane impedance as functions of frequency for model LSO neurons of different speeds (slow, moderate, HL-quick, brisk, fast, and very fast; according to their membrane time constants, see below) (Fig. 3), based on the membrane potential evoked by injected transmembrane current containing a linear frequency sweep from 1 to $2000 \mathrm{~Hz}$, over a duration of one second (Hutcheon \& Yarom, 2000; Puil et al., 1986; Remme et al., 2014). The membrane impedance of each model neuron is a low-pass function of frequency: non-zero at frequency zero and ultimately decreasing with higher frequency, describing membrane voltage that responds to a static input current, and ultimately responds progressively less to input currents of higher frequency.

Our slow, moderate, and HL-quick model LSO neurons have non-resonant, low-pass membrane impedances. The slow model neuron has high membrane impedance, maximum magnitude 713 mega-ohms $(\mathrm{M} \Omega)$ at $3 \mathrm{~Hz}$, magnitude $704 \mathrm{M} \Omega$ at $1 \mathrm{~Hz}$, and a low-pass cut-off $(-3 \mathrm{~dB})$ frequency of $21 \mathrm{~Hz}$, obtained by applying a model membrane for a ventral-cochlear-nucleus (VCN) stellate cell (Type 1c) (Rothman \& Manis, 2003). With higher membrane impedance, lower cut-off frequency, and slower membrane time constant than observed LSO neurons, the slow model neuron will illustrate that even the slowest of LSO neurons can be sensitive to ITD ENv. The moderate model neuron resembles typical non-resonant LSO neurons (Barnes-Davies et al., 2004; Remme et al., 2014), with moderate membrane impedance, maximum magnitude 143 $\mathrm{M} \Omega$ at $3 \mathrm{~Hz}$, magnitude $142 \mathrm{M} \Omega$ at $1 \mathrm{~Hz}$, and a low-pass cut-off frequency of $53 \mathrm{~Hz}$. The HLquick model neuron resembles an observed medial LSO neuron (Remme et al., 2014), with low membrane impedance (Fig. 3, top row: solid cyan line), maximum magnitude $41 \mathrm{M} \Omega$ at $35 \mathrm{~Hz}$, magnitude $37 \mathrm{M} \Omega$ at $1 \mathrm{~Hz}$, and a low-pass cut-off frequency of $395 \mathrm{~Hz}$. With reduced duration, $190 \mathrm{~ms}$ vs. $450 \mathrm{~ms}$, in the bias current before adding the frequency sweep (see Methods), membrane impedance of the HL-quick model neuron increases below $60 \mathrm{~Hz}$ (Fig. 3, top row: dashed cyan line), consistent with the membrane impedance measured in the real neuron.

Our brisk, fast, and very fast model neurons feature model $\mathrm{K}_{\mathrm{LT}}$ channels, and resonant low-pass membrane impedances, as in LSO neurons expressing $\mathrm{K}_{\mathrm{LT}}$ channels (Barnes-Davies et al., 2004; Remme et al., 2014). $\mathrm{K}_{\mathrm{LT}}$ channels produce transmembrane current that opposes depolarization (Manis \& Marx, 1991), analogous to inductive current in an underdamped parallel RLC circuit, and producing a similar characteristic resonance peak in membrane impedance (Nilsson \& Riedel, 2008). The fast model LSO neuron (Rothman \& Manis, 2003; Wang \& Colburn, 2012) has low membrane impedance, with peak magnitude $40 \mathrm{M} \Omega$ at its resonance frequency of $249 \mathrm{~Hz}$. The brisk model LSO neuron has higher membrane impedance, with a less prominent peak in magnitude of $60 \mathrm{M} \Omega$ at a lower resonance frequency, $173 \mathrm{~Hz}$. The very fast model LSO neuron has lower membrane impedance, with a more prominent peak in magnitude of $24 \mathrm{M} \Omega$ at a higher resonance frequency, $355 \mathrm{~Hz}$. 

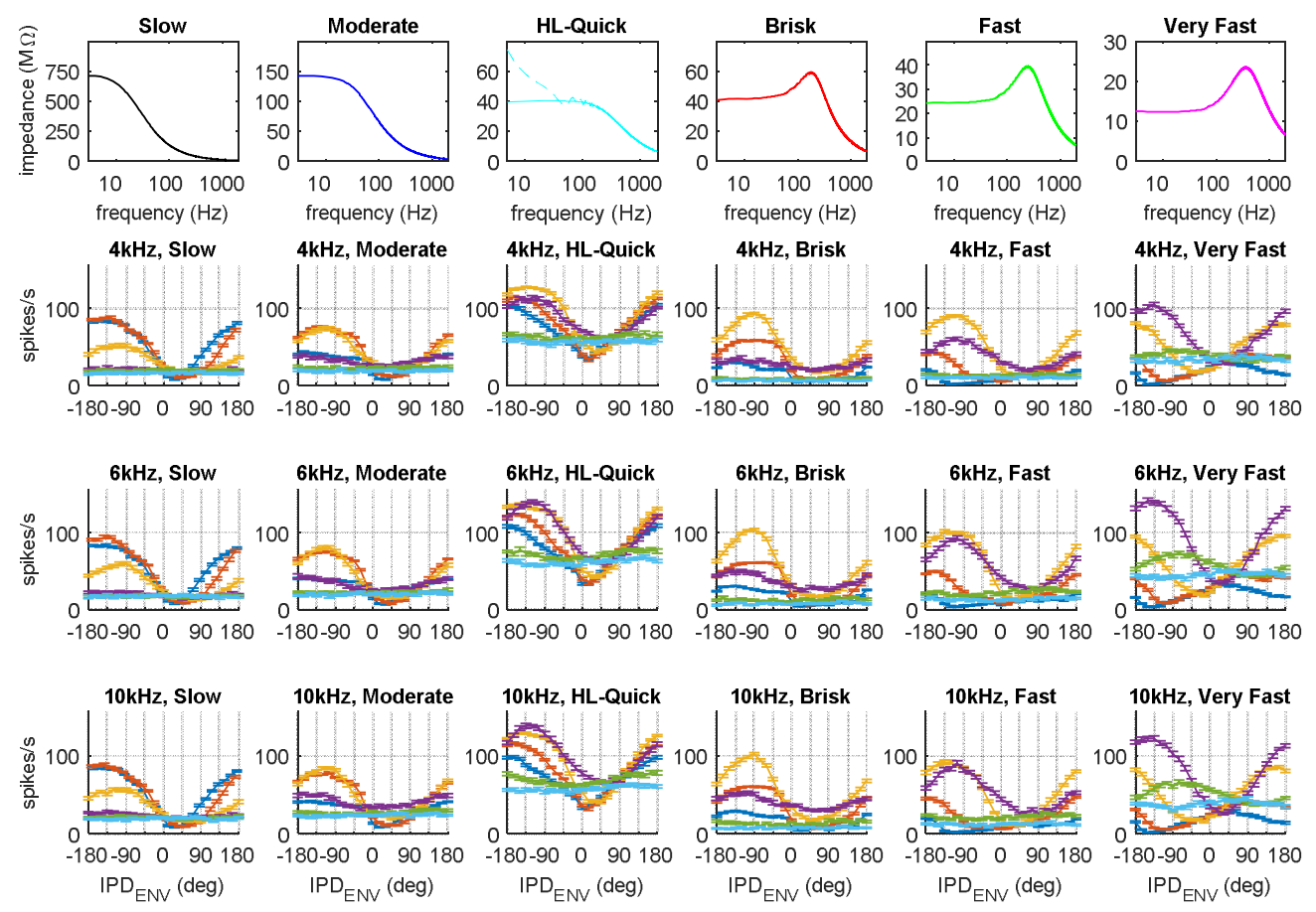

Fig. 3. Membrane impedance and responses to transposed tones in model LSO neurons. Top row: Membrane impedance magnitude as functions of frequency in model LSO neurons of different membrane time constants: slow, moderate, HL-quick, brisk, fast, and very fast. Slow, moderate and HL-quick model neurons have non-resonant, low-pass membrane impedances. Brisk, fast, and very fast model neuronal membranes have model $\mathrm{K}_{\mathrm{LT}}$ channels and resonant, low-pass membrane impedances. Lower 3 rows: Responses to on-frequency listening in populations of 24 model LSO neurons of each membrane speed: mean spike rate and standard error of the mean as functions of IPD $D_{E N V}$ (interaural phase difference with respect to the amplitude-modulation cycle). The title of each panel gives the stimulus carrier frequency, and membrane speed of the model LSO neurons. For on-frequency listening, the characteristic frequency (CF, the frequency of lowest spike-threshold in SPL) of model ANFs driving the model LSO neurons, was set equal to the carrier frequency. Responses are to the $25^{\text {th }}$ stimulus repetition, a separate curve for each modulation rate. The legend within the figure shows modulation rates

Each type of model LSO neuron is distinct in the frequency response of its membrane impedance (Fig. 3), with the resulting calculated membrane time constant: slow $(7.6 \mathrm{~ms})$, moderate $(3.0 \mathrm{~ms})$, HL-quick $(0.48 \mathrm{~ms})$, brisk $(0.92 \mathrm{~ms})$, fast $(0.64 \mathrm{~ms})$, and very fast $(0.45 \mathrm{~ms})$. In non-resonant membranes, a first-order system, the calculated membrane time constant is equal to the reciprocal of the low-pass cut-off frequency (the -3-dB frequency, in radians per second); in resonant membranes, a second order system, the calculated membrane time constant is equal to the reciprocal of the resonance frequency (in radians per second) (Nilsson 
\& Riedel, 2008). A neuron with a faster membrane time constant can effectively pass higher frequencies from its input current to its membrane potential. With faster membrane time constants and lower membrane impedance, model synapses were made faster and stronger to maintain action potentials (Sterenborg et al., 2010). Across neuronal speeds, model inhibitory synapses maintained double the time constant, and 10 times the strength, of model excitatory synapses.

\section{Membrane frequency response influences ITD $D_{E N V}$ sensitivity in model LSO neurons}

For populations of 24 model LSO neurons of each speed (slow, moderate, HL-quick, brisk, fast, and very fast), binaurally stimulated by transposed tones, we plotted mean spike rate as a

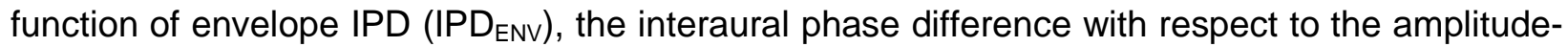
modulation cycle (Fig. 3). The transposed tones were of 300-ms duration, with maximum sound pressure level (SPL) $75 \mathrm{~dB}$ RMS, at carrier frequencies of 4,6 , and $10 \mathrm{kHz}$, and modulation rates of $32,64,128,256,512$, and $800 \mathrm{~Hz}$. The transposed tones stimulate a bilateral-auditoryperiphery model containing stochastic model auditory-nerve (AN) fibers (Zilany et al., 2014) of characteristic frequency (CF, the frequency of lowest spike-threshold in SPL) equal to the stimulus carrier frequency. Model ANFs directly drive the 40 ipsilateral excitatory synapses and 8 contralateral inhibitory synapses of each model LSO neuron (Fig. 1B), where membrane impedance low-pass filters the inputs driven by amplitude-modulated sound, limiting the upper modulation rate for sensitivity to ITD ENV.

Reasonably consistent with the frequency response of its membrane impedance, each model population of LSO neurons generates spike rates that are most sensitive to IPD ENV for a particular range of modulation rate. Slow model neurons are most sensitive for modulation at 32 and $64 \mathrm{~Hz}$. Moderate model neurons are most sensitive for modulation at 64 and $128 \mathrm{~Hz}$, with lower sensitivity at $32 \mathrm{~Hz}$ and still less sensitivity at $256 \mathrm{~Hz}$. HL-quick model neurons are most sensitive for modulation at 128 and $256 \mathrm{~Hz}$, with lower sensitivity for $32-\mathrm{Hz}$ and $64-\mathrm{Hz}$ modulation. At 32- $\mathrm{Hz}$ modulation, slow model neurons have steep spike-rate functions of IPD $\mathrm{ENV}_{\mathrm{E}}$ (rate-IPD $D_{E N V}$ functions), spiking from near zero to three times during the 31.25-ms modulation cycle; moderate model neurons do not spike repeatedly, yet their rate-IPD $\mathrm{ENV}_{\text {functions }}$

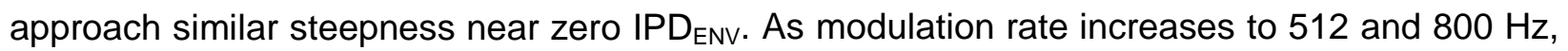
slow, moderate, and HL-quick model neurons become quite insensitive to IPD ENv. Brisk model neurons are most sensitive for modulation at 64 and $128 \mathrm{~Hz}$, with lower sensitivity at 32 and 256 $\mathrm{Hz}$. Fast model neurons are most sensitive for modulation at 128 and $256 \mathrm{~Hz}$. Very fast model neurons are most sensitive for modulation at $256 \mathrm{~Hz}$, and sensitive at 128 and $512 \mathrm{~Hz}$. With

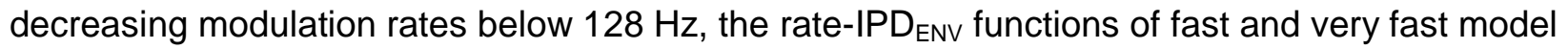
neurons decrease in slope, and their steepest slopes occur far from zero IPD ENv.

At high modulation rates of 512 and $800 \mathrm{~Hz}$, modulation output is increased by band-pass filters centered above the carrier frequency (Monaghan et al., 2015). We investigated this 'offfrequency listening' at $512-\mathrm{Hz}$ and $800-\mathrm{Hz}$ modulation, using populations of brisk, HL-quick, fast, and very fast model LSO neurons, stimulated by model ANFs with CF between the carrier frequency and the first upper modulation sideband of each transposed tone. At these high modulation rates, for brisk model neurons, neither this off-frequency listening, nor the original on-frequency listening (CF at the carrier frequency), produced measurable JNDs in ITD ENV. For HL-quick model neurons, off-frequency listening did not produce a measureable JND, and onfrequency listening produced a measurable JND in only one condition. For fast and very fast model neurons, compared with model neurons of the same membrane speed with CFs at the carrier frequency, off-frequency listening produced some small increases in sensitivity to ITD ENV 
(Fig. 4), sufficient generally to improve neural JNDs in ITD ENv, including three conditions requiring off-frequency listening to produce a measurable JND (JNDs shown below in Fig. 5). For fast and very fast model neurons, each condition in which on-frequency listening produced a measurable JND, off-frequency listening also produced a measurable JND.

Overall, neural tuning for ITD $\mathrm{ENV}_{\mathrm{N}}$ depends on membrane speed. Model neurons with relatively slow membranes-characterized by high input impedances and low-pass electrical filters of low cut-off frequency-are most suited to extracting ITDs from slowly modulated sounds, and neurons with faster membranes less so. As modulation rate increases, model neurons with faster membrane properties-low input impedance with a high-frequency resonance or cut-offshow relatively greater sensitivity to $I T D_{E N V}$ compared to neurons with slow membrane properties.
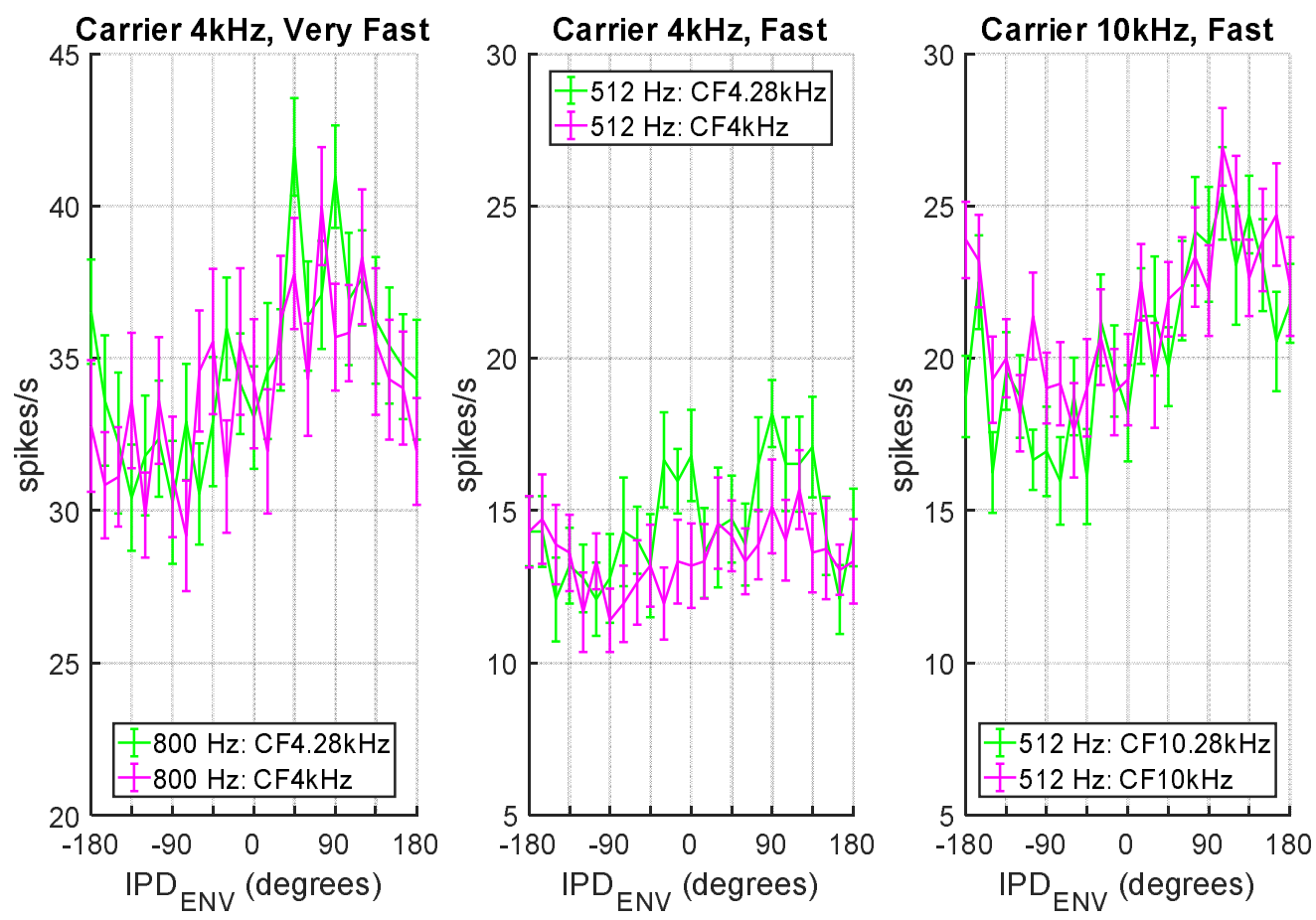

Fig. 4. Model LSO neurons: on- and off-frequency listening. Mean spike rates as functions of IPD $\mathrm{ENV}_{\text {in }}$ populations of 24 model LSO neurons, for three stimulus-and-model conditions in which off-frequency listening produced a measurable JND and on-frequency listening did not (stimulus repetition 25, for all conditions). The title of each panel gives the carrier frequency of the transposed tone stimulus, and the membrane speed of model LSO neurons. The legend within each panel shows modulation rate and CF of the model neurons. Error bars show standard error of the mean spike rate. The criterion for a valid JND is agreement in the algebraic

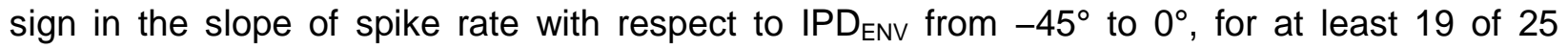
stimulus repetitions. For these three conditions of off-frequency listening (CF between the

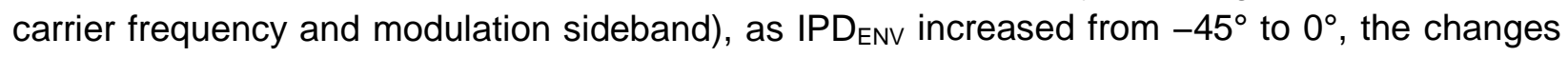
in spike rate were positive, agreeing with the trend in slope across the conditions. For on-

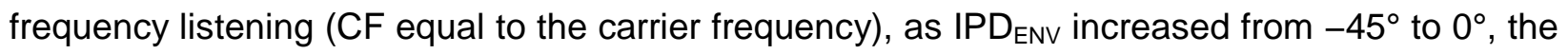
changes in spike rate were negative, positive, and near zero for one condition each, suggesting how on-frequency listening failed to meet the criterion for a measurable JND within each condition 


\section{Just-noticeable differences in ITD $D_{E N V}$ : humans and model LSO neurons}

Using the spike-rate responses to transposed tones, we calculated JNDs in ITDENV for our

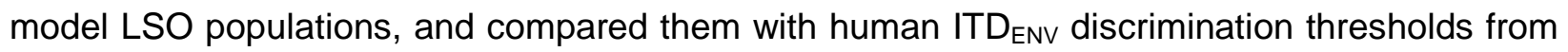
published reports (Fig. 5). For the models, modulation rates were 32, 64, 128, 256, 512, and $800 \mathrm{~Hz}$. In the human studies, modulation rates ranged from 32 to $512 \mathrm{~Hz}$ (Bernstein \& Trahiotis, 2002), and from 128 to $800 \mathrm{~Hz}$ (Monaghan et al., 2015).

For each stimulus repetition and model population, a neural JND (Brown \& Tollin, 2016) was calculated as the standard error of the mean spike rate, divided by the derivative of mean spike rate with respect to ITD. Agreement in the algebraic sign of the derivative in at least 19 of the 25 stimulus repetitions was required. If this criterion was met, the geometric mean and standard deviation of the absolute values in JND were then calculated and plotted, using all finite JNDs from the 25 stimulus repetitions. If this criterion was not met, the JND was considered to be unmeasurably high (i.e. the task was impossible).

For transposed tones at $4 \mathrm{kHz}$, human JNDs in TTD $_{\text {ENV }}$ are lowest (performance is best) at 128$\mathrm{Hz}$ modulation. At higher modulation-rates, performance worsens (JNDs increase), and eventually the task becomes impossible: all the human listeners were able to perform the task at $256-\mathrm{Hz}$ modulation; 5 of 9 listeners were capable at $512-\mathrm{Hz}$ modulation; 2 of 5 at $600-\mathrm{Hz}$ and $700-\mathrm{Hz}$; and 1 of 5 at $800-\mathrm{Hz}$ (Bernstein \& Trahiotis, 2002; Monaghan et al., 2015). Slow and moderate model LSO neurons generally reflected a competent level in average human performance for modulation from 32 to $128 \mathrm{~Hz}$ (Bernstein \& Trahiotis, 2002), but then worsened to reflect below-average human performance at $256-\mathrm{Hz}$ modulation. At modulation rates above $32 \mathrm{~Hz}$, top human performance was reflected by the best-performing model populations: this included brisk and moderate model neurons at $64-\mathrm{Hz}$ modulation, HL-quick and fast model neurons at $128-\mathrm{Hz}$ modulation, and very fast model neurons at $256-$ to $800-\mathrm{Hz}$ modulation, requiring off-frequency listening at $800-\mathrm{Hz}$. At $4 \mathrm{kHz}, 256-\mathrm{Hz}$ modulation is a condition where the range of model neuronal membranes produces JNDs spanning the largest human range of JNDs. At 128- $\mathrm{Hz}$ modulation, the condition of lowest human JND (Monaghan et al., 2015), model membrane speed does not account for poor human performance, as very fast model neurons performed still worse, and slow-to-fast model populations performed better. 

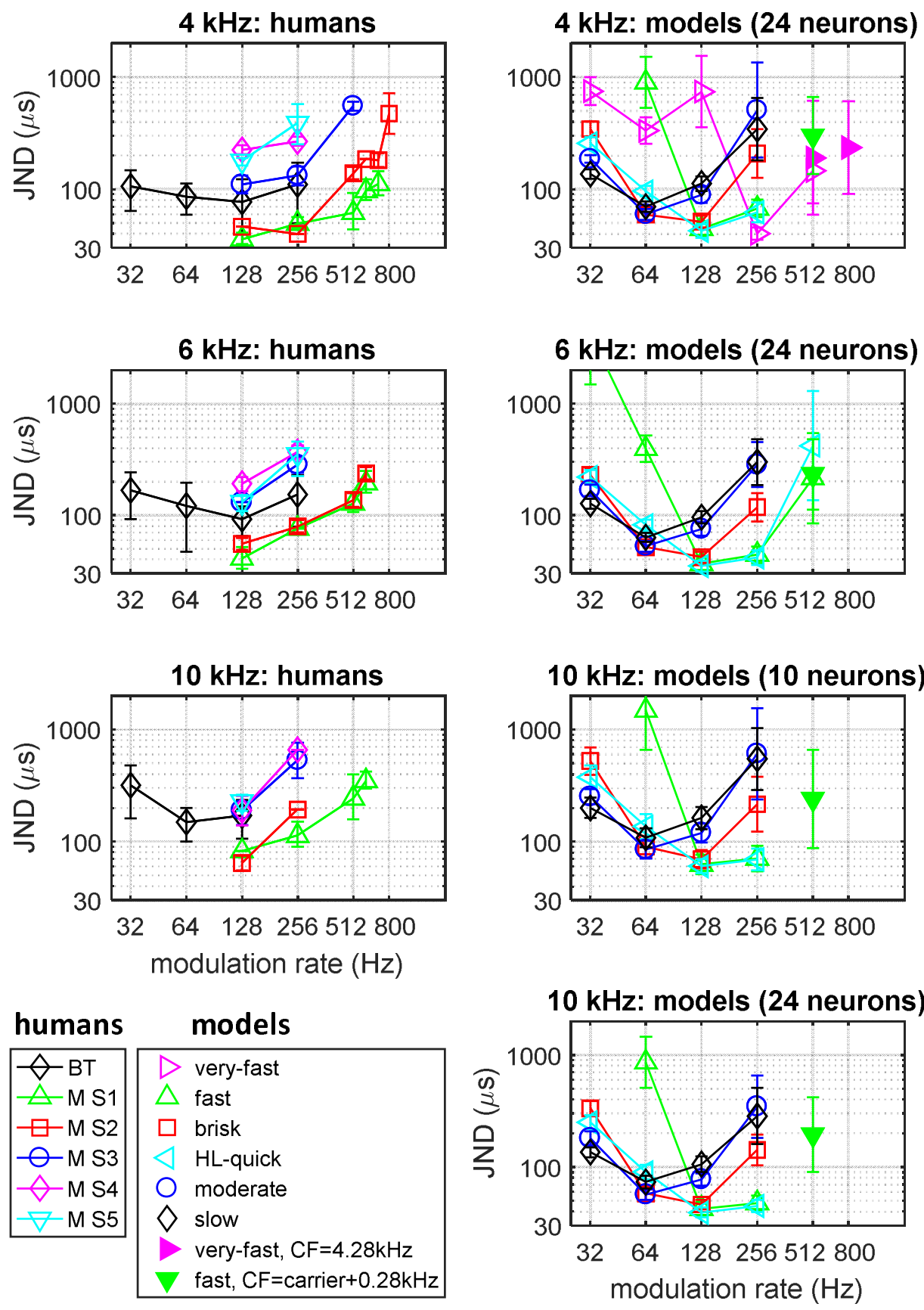

Fig. 5. Just-noticeable differences (JNDs) in ITD $\mathrm{ENV}_{\mathrm{N}}$ as functions of modulation rate in transposed tones at carrier frequencies of 4,6 , and $10 \mathrm{kHz}$. The title of each panel includes the

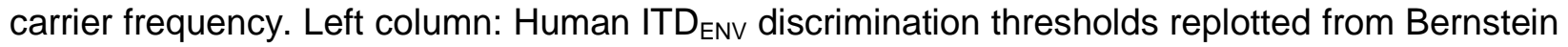
and Trahiotis (2002) (BT, arithmetic mean and standard deviation across listeners) and from (Monaghan et al., 2015) (geometric mean and standard deviation for each listener, M S1 thru M S5). Right column: Neural JNDs in ITD ENv calculated for populations of 10 or 24 model LSO neurons (geometric mean and standard deviation across 25 stimulus repetitions). These populations are distinct in membrane time constant: slow, moderate, HL-Quick, brisk, fast, and very fast. Model neurons generally applied on-frequency listening: CF equal to the carrier frequency. At high modulation rates, additional populations of fast and very fast model neurons applied off-frequency listening: CF between the carrier frequency and modulation sideband, as shown in the legend within the figure 
For transposed tones at $6 \mathrm{kHz}$, human JNDs in ITD ENV are again lowest at 128- $\mathrm{Hz}$ modulation, and increase with higher modulation rates. Human JNDs increase slightly overall compared with $4 \mathrm{kHz}$, yet all human listeners capably performed the task at 256- $\mathrm{Hz}$ modulation; 4 of 9 were capable at $512-\mathrm{Hz}$ modulation; and 2 of 5 at $600-\mathrm{Hz}$ (Bernstein \& Trahiotis, 2002; Monaghan et al., 2015). Consistent with broadening auditory filters at higher CF better passing the spectral modulation sidebands of amplitude-modulated sounds, JNDs of the model populations with 24 neurons decreased slightly, compared with those for transposed tones at $4 \mathrm{kHz}$. Slow and moderate model neurons reflected average to above-average human performance from 32- to $128-\mathrm{Hz}$ modulation, and below-average performance at $256-\mathrm{Hz}$ modulation. At modulation rates above $32 \mathrm{~Hz}$, the best performing model populations generally reflected top human performance: which was approached by moderate and brisk model neurons at $64-\mathrm{Hz}$ modulation, reflected by $\mathrm{HL}$-quick, brisk and fast model neurons at $128-\mathrm{Hz}$ modulation, spanned by brisk to fast and $\mathrm{HL}$-quick model neurons at $256-\mathrm{Hz}$ modulation, and matched by fast model neurons at $512-\mathrm{Hz}$ modulation using either on-frequency or off-frequency listening. At $128-\mathrm{Hz}$ modulation, a condition with generally very low JNDs for humans (Bernstein \& Trahiotis, 2002; Monaghan et al., 2015), model membrane speed does not account for poor human performance, as slow to fast model populations all performed better. Consistent with the lower proportion of fast resonant LSO neurons at higher CFs (Remme et al., 2014): slow to fast model neurons were sufficient to match human ITD ENV sensitivity; at 6 and $10 \mathrm{kHz}$, very fast model neurons were not required to match human performance.

For transposed tones at $10 \mathrm{kHz}$, human JNDs increase relative to those at $6 \mathrm{kHz}$. For humans and model neurons, JNDs in ITD ENv at $10 \mathrm{kHz}$ are generally lowest at $64-\mathrm{Hz}$ and $128-\mathrm{Hz}$ modulation. At higher modulation rates, performance worsens: 7 of 9 human listeners capably performed the task at 256- $\mathrm{Hz}$ modulation; 2 of 9 were capable at $512-\mathrm{Hz}$ modulation; and 1 of 5 at $600-\mathrm{Hz}$ (Bernstein \& Trahiotis, 2002; Monaghan et al., 2015). Maintaining populations of 24 model neurons, the top-performing model neurons generally exceeded top human performance. Reducing each population to 10 model neurons restored the match of human performance. Slow and moderate model neurons reflected average to above-average human performance from 32- to $128-\mathrm{Hz}$ modulation, and below-average performance at $256-\mathrm{Hz}$ modulation. Top human performance was approached by moderate and brisk model neurons at $64-\mathrm{Hz}$ modulation; reflected by $\mathrm{HL}$-quick, fast, and brisk model neurons at $128-\mathrm{Hz}$ modulation; spanned by brisk to fast and $\mathrm{HL}$-quick model neurons at $256-\mathrm{Hz}$ modulation; and matched by fast model neurons at $512-\mathrm{Hz}$ modulation using off-frequency listening. At $128-\mathrm{Hz}$ and $256-\mathrm{Hz}$ modulation, model membrane speed largely accounts for the range of human performance. However, at $64-\mathrm{Hz}$ modulation, which has the lowest measured mean JND at $10 \mathrm{kHz}$ for humans (Bernstein \& Trahiotis, 2002), model membrane speed does not account for poor human performance, as fast model neurons performed still worse, and slow, moderate, HLquick, and brisk model populations performed better. Considering 4-, 6-, and 10-kHz carriers, at modulation rates where human ITD ENV sensitivity is generally the best, model membrane speed does not account for poor human performance; then at higher modulation rates where human ITD ENV sensitivity decreases, the range in model membrane speeds produces JNDs in ITD ENV which reflect the range of human performance.

Consistent with the paradoxical reduction in ITD ENV sensitivity with increasing sound frequency observed behaviorally in humans (Bernstein \& Trahiotis, 2002; Monaghan et al., 2015): reducing each population to 10 model neurons at $10 \mathrm{kHz}$ increased JNDs relative to those at $6 \mathrm{kHz}$ for the same modulation rate, and provided a similar fit to human performance to those of the populations of 24 model neurons at 4 and $6 \mathrm{kHz}$. 


\section{Effects of carrier frequency}

As carrier frequency increases, sensitivity to $I T D_{E N V}$ in human listeners decreases (JNDs increase). This decreasing sensitivity with increasing sound frequency is paradoxical, as cochlear band-pass filters broaden in absolute bandwidth with higher CF (Glasberg \& Moore, 1990), thereby more strongly passing the modulation sidebands of amplitude-modulated stimuli. Consistent with increasing peripheral bandwidth, at $256-\mathrm{Hz}$ modulation with increasing carrier frequency from 4 to $6 \mathrm{kHz}$, for brisk and fast model neurons we find slightly elevated modulation in spike rate as a function of IPD ENV (Fig. 3), and slightly reduced (improved) JNDs in ITD ENV (Fig. 5). Similar increases in spike-rate modulation occur in very fast model neurons for $800-\mathrm{Hz}$ modulation, for increasing carrier frequencies from 4 to 6 to $10 \mathrm{kHz}$ (Fig. 3). For slow to fast model neurons, the steady JNDs between 6 and $10 \mathrm{kHz}$ when maintaining 24 model neurons per population (Fig. 5) suggest that the model cochlear filters have sufficient bandwidth at $6 \mathrm{kHz}$ to pass relevant sidebands for modulation up to $256 \mathrm{~Hz}$. The increasing human JNDs (decreasing sensitivity) with higher carrier frequency may be explained by decreasing numbers of stimulated auditory neurons with higher CF, as suggested to occur in "hidden" hearing loss (Plack et al., 2014). When the number of model neurons was reduced to 10 per population at 10 $\mathrm{kHz}$ (maintaining 24 model neurons per population at 4 and $6 \mathrm{kHz}$ ), JNDs increased from 6 to $10 \mathrm{kHz}$ (Fig. 5), reproducing the paradoxical reduction in ITD $_{\text {ENV }}$ sensitivity with increasing sound frequency.

\section{Effects of modulation rate}

For humans and our models, JNDs in ITD ENv are lowest (performance is best) at $64-\mathrm{Hz}, 128-\mathrm{Hz}$, or $256-\mathrm{Hz}$ modulation. Halving the modulation rate, the same change in spike rate for IPDENV between $-45^{\circ}$ and $0^{\circ}$ (Fig. 3) produces double the JND in ITD ENV (Fig. 5). With increasing modulation rate, although this effect becomes an advantage, it is overcome by decreasing membrane impedance that reduces the response of a model neuronal membrane to synaptic currents: performance worsens, and eventually the task becomes impossible. At modulation rates of $256 \mathrm{~Hz}$ and above, the large variance in human ITD ENV sensitivity including unmeasurable JNDs is reflected by the JND range of the model neuronal populations.

\section{Effects of off-frequency listening}

Modulation at 512 and $800 \mathrm{~Hz}$ in the output of auditory-like gammatone filters is greater for filters centered above the carrier frequency, compared with gammatone filters centers at the carrier (Monaghan et al., 2015). Accordingly, with off-frequency listening, modeled by applying inputs from model ANFs of CF between the carrier frequency and first upper modulation sideband: at $512-\mathrm{Hz}$ and $800-\mathrm{Hz}$ modulation, JNDs in ITD ENV are generally lower (better performance) for fast and very fast model LSO neurons, when compared with JNDs for model neurons of the same speed with inputs of CF at the carrier frequency. For multiple stimulus conditions, off-frequency listening provided a measurable JND, when on-frequency listening did not (Fig. 5). This suggests that the very best listeners, in terms of $I T D_{\text {ENV }}$ discrimination performance, can access relatively small fluctuations in neural activity in frequency channels beyond that of the stimulus center-frequency to perform discrimination tasks, and that this offfrequency listening performance still requires the existence of fast and very-fast LSO neurons to extend to frequencies beyond the range of average-performing listeners. 


\section{Discussion}

We explored sensitivity to ITD ENV in computationally modeled LSO neurons in potentially explaining human behavioral discrimination of ITD $_{\mathrm{ENV}}$ in high-frequency amplitude-modulated sound. In particular, we evaluated the influence of electrical impedance of neuronal membranes on discrimination performance as a function of the modulation rate and carrier frequency of sound. Transposed tones stimulated an auditory-periphery model bilaterally innervating the model LSO neurons. Collectively reflecting human abilities to discriminate ITD $_{\text {ENV }}$, neural JNDs in ITD ENV were calculated for model neuronal populations, distinct in membrane frequency response reflecting the LSO range, with time constants from slow to very fast. Within these model neurons, electrical membrane impedances similar to those in LSO neurons decrease with increasing frequency, and limit the upper modulation rate for sensitivity to ITD ENV, by low-pass filtering binaural inputs driven by amplitude-modulated sound. Yet, rather than very fast model neurons with the widest bandwidth being best overall, each speed of model neuron produced the lowest JNDs in ITD ENV for a particular range of modulation rate: slow model neurons at 32 $\mathrm{Hz}$; moderate model neurons at $64 \mathrm{~Hz}$; brisk model neurons from 64 to $128 \mathrm{~Hz}$; fast and HLquick model neurons from 128 to $256 \mathrm{~Hz}$; and very fast model neurons from 256 to $800 \mathrm{~Hz}$. Across modulation rates, top sensitivity to ITD ENV leveraged model neurons of all speeds from slow to very fast. Although the slowest LSO neurons may not be quite as slow as the slow model neurons, which illustrate the capacity for ITD ENV sensitivity in slow neurons, JNDs at 32$\mathrm{Hz}$ modulation were nearly as low for moderate model neurons, suggesting that moderate LSO neurons may combine with slightly slower LSO neurons to lower the JND at 32- $\mathrm{Hz}$ modulation. With compatible inputs and synapses, our models suggest that ITDENV can be well encoded collectively by LSO neurons of the observed range in membrane properties.

Our model neuronal populations reflect the dependence of human $I T D_{E N V}$ sensitivity on the carrier frequency and modulation rate of sound, including the ultimate reduction in sensitivity with increasing modulation rate, and the paradoxical reduction in sensitivity with increasing carrier frequency, modeled here by the combination of reduced top membrane speed, and a reduced number of stimulated neurons as suggested to occur in "hidden" hearing loss (Plack et al., 2014). In each stimulus condition, across carrier frequency (4-10 kHz) and modulation rate $(32-800 \mathrm{~Hz})$, top-range human sensitivity to ITD ENV is generally reflected by the top-performing population of model LSO neurons. Off-frequency listening in fast and very fast model neurons, with CFs between the carrier frequency and modulation sideband, helped to extend ITD $\mathrm{ENV}$ sensitivity to modulation rates above $500 \mathrm{~Hz}$. Reflecting the range in low-pass-filter properties of LSO neuronal membranes (Remme et al., 2014), the model neuronal populations collectively reproduce the largest (ten-fold) variation in measurable JNDs for ITD ENv across human listeners, which occurs at $4 \mathrm{kHz}$ with 256-Hz modulation (Monaghan et al., 2015), and is larger than the variation in behavioral thresholds for ITD TFS (Bernstein \& Trahiotis, 2002).

Early interpretation of differences in human ability to exploit ITD $D_{\text {TFS }}$ and ITD $D_{\text {ENV }}$ focused on differences in the peripheral representation of low- and high-frequency sounds. The Colburn and Esquissaud (1976) hypothesis posits equivalent sensitivity to ITD TFS and ITD ENV, if peripheral representations of low-frequency sounds and high-frequency modulated sounds are matched prior to binaural integration. Bernstein and Trahiotis (2002) explored this concept employing transposed tones of modulation frequencies equal to the frequencies of lowfrequency tones. Despite asserting approximately equivalent sensitivity for ITD $D_{T F S}$ and ITD $D_{\text {ENV, }}$ human discrimination thresholds in ITD ENV were actually substantially better at the lowest 
modulation frequencies for transposed tones (32 and $64 \mathrm{~Hz}$ ) than they were for pure tones of 32 and $64 \mathrm{~Hz}$ (Bernstein \& Trahiotis, 2002). A plausible explanation is that the relatively fast MSO neurons encoding ITD TFS are less able to encode ITD information at 32 and $64 \mathrm{~Hz}$, than LSO neurons with moderate to reasonably slow, more integrative, membrane properties when operating at similarly slow modulation rates.

Contrasting with improving performance in ITD TFS up to at least $700 \mathrm{~Hz}$ and sensitivity to 1400 $\mathrm{Hz}$ (Brughera et al., 2013), as modulation frequencies increase beyond $128 \mathrm{~Hz}$, Bernstein and Trahiotis (2002) suggested that a low-pass modulation filter, initially proposed with a corner frequency of $150 \mathrm{~Hz}$, would explain the declining sensitivity to ITD ENV. While explaining average performance of their four listeners, this filter poorly fit individual listeners: one listener had comparable thresholds for ITD ENV at $512-\mathrm{Hz}$ modulation, and ITD $\mathrm{TFS}_{\mathrm{T}}$ thresholds at the same pure-tone frequencies; the remaining three listeners showed ten-fold increases in their ITD ENV thresholds, or were unable to perform the task. Error bars, for the average performance of these four listeners, indicate their range of performance at 128 and $256 \mathrm{~Hz}$ is similar to that of individual thresholds for the five listeners in Monaghan et al. (2015). We modelled this decline in performance between listeners as decreasing access to LSO neurons with relatively high membrane speeds, which are produced in vivo by the expression of ion channels. Decreasing access to LSO neurons with high membrane speeds also helped reproduce the worsening of ITD ENV performance with increasing CF. Considered across listeners and CFs, availability of LSO neurons with high membrane speeds would explain the fact that listeners with the lowest ITD ENV thresholds at 128 and $256 \mathrm{~Hz}$ for a $4-\mathrm{kHz}$ carrier frequency were invariably those for whom ITD ENV remained discriminable at higher modulation rates and at higher carrier frequencies. The practical low-pass modulation filter is carrier-frequency dependent (Bernstein \& Trahiotis, 2014), and varies across human listeners for the same modulation and carrier frequencies, consistent with our modelling data. This suggests a fundamental determinant of ITD ENV sensitivity might be the ability of different listeners to access fast LSO membrane properties. Heterogeneity in the expression of ion channels is a systemic feature of physiology (Schulz et al., 2006; Veerman et al., 2017), suggesting a cogent explanation for the inter-subject variability.

\section{Complimentary cues in auditory spatial encoding}

Categorical, cyclic, and non-cyclic continuous-scale encoding of auditory spatial cues may together support accurate sound-source localization. The brain may disambiguate the cyclic encoding of ITDs in the MSO and LSO (Batra et al., 1997), by applying non-cyclic encoding of IIDs by non-principal LSO neurons (Boudreau \& Tsuchitani, 1967), and categorical encoding of onset IID by principal LSO neurons (Franken et al., 2018), combined with processing of categorical front/back and up/down spectral distinctions in pinnae acoustics (Langendijk \& Bronkhorst, 2002). Consistent with recent definitions (Franken et al., 2018): principal LSO neurons refer to resonant LSO neurons with bipolar dendrites, and non-principal LSO neurons include non-resonant LSO neurons. Although suggesting a mechanism for observed psychophysical lateralization based on the leading ear when presented with confounding ITD cues (Stern \& Shear, 1996; Thompson et al., 2006; von Kriegstein et al., 2008), onset-IID responses to unmodulated high-frequency tones in six principal LSO neurons (Franken et al., 2018) do not preclude the well-documented sensitivity of LSO neurons to ITD ENV in highfrequency amplitude-modulated sound (Batra et al., 1997; Joris \& Yin, 1995, 1998). Reflecting behavioral sensitivity, neural sensitivity to static ITD ENV decreases with increasing modulation rate, yet can show clear modulation in spike rate at $500-\mathrm{Hz}$ modulation, persisting at $750-\mathrm{Hz}$ 
modulation (Joris, 1996). Depending on their inputs and membranes, principal or non-principal neurons may contribute to these responses.

Stimuli, neurons, and encoding mechanisms differ between ITD TFS and ITD ${ }_{E N V}$ Overall, MSO neurons encoding ITD $\mathrm{TFS}_{\mathrm{T}}$ have advantages over LSO neurons encoding ITD $\mathrm{ENV}_{\text {. }}$

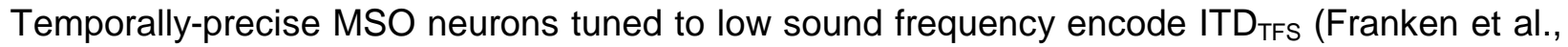
2015; Yin \& Chan, 1990), applying binaural-coincidence-detection mechanisms sharpened by $\mathrm{K}_{\mathrm{LT}}$ channels (Mathews et al., 2010), as dendritic mechanisms emphasize binaural relative to monaural coincidences (Dasika et al., 2007; Scott et al., 2010). With high-frequency amplitudemodulated sound, modulation rate is limited by the bandwidth of cochlear filters, and phaselocking in the AN is generally lower even for transposed tones than for low-frequency tones (Dreyer \& Delgutte, 2006). Despite these peripheral effects, a high-frequency MSO neuron was quite sensitive to ITD ENV for $1000-\mathrm{Hz}$ modulation (Yin \& Chan, 1990). Although some LSO neurons express $\mathrm{K}_{\mathrm{LT}}$ channels (Barnes-Davies et al., 2004), LSO neurons do not benefit from binaural-coincidence detection, instead relying on the anti-coincidence of ipsilateral excitation and contralateral inhibition (Batra et al., 1997). LSO neurons with slowly-responding membranes lacking $\mathrm{K}_{\mathrm{LT}}$ channels become increasingly common in higher-frequency LSO regions (Barnes-Davies et al., 2004; Remme et al., 2014). The temporal and frequency limits of LSO neurons appear to shape the modulation-rate limits of ITD ENV sensitivity.

\section{Implications for listeners with bilateral cochlear implants (Cls, bCls)}

Unlike in normal-hearing listeners leveraging the advantages of ITD unmasking can be about equal for envelope cues, compared with fine-structure cues (van Hoesel et al., 2008). For bCl stimulation at high pulse rates typical of clinical $\mathrm{Cl}$ processors, bCl listeners achieve about $9 \mathrm{~dB}$ of binaural unmasking when the temporal envelope is presented without fine structure using constant-rate pulses (Todd et al., 2019). This benefit from binaural envelope cues may be largely from IID with only minor support from ITD ENV, consistent with the much heavier weighting of IID than of ITD for localizing high-frequency sound, by the large majority of normal-hearing listeners (Macpherson \& Middlebrooks, 2002).

Considerable effort is showing how bCl listeners might further benefit from binaural localization cues (Kan et al., 2019, 2015; Laback et al., 2011; Monaghan \& Seeber, 2016; Stakhovskaya \& Goupell, 2017), and notably in conveying electrical ITD to bCl listeners using bilateral pulseburst stimulation (Srinivasan et al., 2020, 2018), which might be incorporated in conveying acoustic ITD TFS, ITD ENv, IID, and speech to bCl listeners. Cl-stimulation rates up to 1000 or 1200 pulses per second would be sufficiently slow to convey coherent ITD cues using pulse bursts, and sufficiently fast to provide speech information (Fu \& Shannon, 2000; Shader et al., 2020; Shannon et al., 2011). A bCl processor can be developed to present electrical pulses synchronous with the TFS of sound at each ear, bilaterally coordinated with pulse bursts, temporal interleaving across electrodes for low- to high-frequency sound, and refractory pauses for high-frequency channels.

\section{Acknowledgments}

\section{Funding}

This work was supported by Australian Research Council Laureate Fellowship (FL160100108) awarded to DM. 


\section{References}

Banks MI, \& Smith PH (1992) Intracellular Recordings from Neurobiotin-labeled Cells in Brain Slices of the Rat Medial Nucleus of the Trapezoid Body. J Neurosci 12(7):2819-2837.

Barnes-Davies M, Barker MC, Osmani F, \& Forsythe ID (2004) Kv1 currents mediate a gradient of principal neuron excitability across the tonotopic axis in the rat lateral superior olive. Eur J Neurosci 19(2):325-333. https://doi.org/10.1111/j.0953-816X.2003.03133.x

Batra R, Kuwada S, \& Fitzpatrick DC (1997) Sensitivity to interaural temporal disparities of lowand high-frequency neurons in the superior olivary complex. I. Heterogeneity of responses. J Neurophysiol 78(3):1222-1236. https://doi.org/10.1152/jn.1997.78.3.1222

Bernstein LR, \& Trahiotis C (2002) Enhancing sensitivity to interaural delays at high frequencies by using "transposed stimuli." J Acoust Soc Am 112(3):1026-1036. https://doi.org/10.1121/1.1497620

Bernstein LR, \& Trahiotis C (2014) Sensitivity to envelope-based interaural delays at high frequencies: Center frequency affects the envelope rate-limitation. J Acoust Soc Am 135(2):808-816. https://doi.org/10.1121/1.4861251

Blauert J (1997) Spatial Hearing: The Psychophysics of Human Sound Localization. MIT Press, Cambridge, MA.

Boudreau JC, \& Tsuchitani C (1967) Binaural Interaction in the Cat Superior Olive S Segment. J Acoust Soc Am 42(5):1207. https://doi.org/10.1121/1.2144209

Brown AD, \& Tollin DJ (2016) Slow Temporal Integration Enables Robust Neural Coding and Perception of a Cue to Sound Source Location. J Neurosci 36(38):9908-9921. https://doi.org/10.1523/JNEUROSCI.1421-16.2016

Brughera A, Dunai L, \& Hartmann WM (2013) Human interaural time difference thresholds for sine tones: The high-frequency limit. J Acoust Soc Am 133(5):2839-2855. https://doi.org/10.1121/1.4795778

Brungart DS, \& Rabinowitz WM (1999) Auditory localization of nearby sources. Head-related transfer functions. J Acoust Soc Am 106(3):1465-1479. https://doi.org/10.1121/1.427180

Colburn HS, \& Esquissaud P (1976) An auditory-nerve model for interaural time discrimination of high-frequency complex stimuli. J Acoust Soc Am 59(S1):S23-S23. https://doi.org/10.1121/1.2002503

Dasika VK, White JA, \& Colburn HS (2007) Simple Models Show the General Advantages of Dendrites in Coincidence Detection. J Neurophysiol 97(5):3449-3459. https://doi.org/10.1152/jn.00669.2005

Doucet JR, \& Ryugo DK (2003) Axonal pathways to the lateral superior olive labeled with biotinylated dextran amine injections in the dorsal cochlear nucleus of rats. J Comp Neurol 461(4):452-465. https://doi.org/10.1002/cne.10722

Dreyer A, \& Delgutte B (2006) Phase Locking of Auditory-Nerve Fibers to the Envelopes of High-Frequency Sounds: Implications for Sound Localization. J Neurophysiol 96(5):23272341. https://doi.org/10.1152/jn.00326.2006

Franken TP, Joris PX, \& Smith PH (2018) Principal cells of the brainstem's interaural sound 
level detector are temporal differentiators rather than integrators. ELife 7:1-25. https://doi.org/10.7554/eLife.33854

Franken TP, Roberts MT, Wei L, Golding NL, \& Joris PX (2015) In vivo coincidence detection in mammalian sound localization generates phase delays. Nat Neurosci 18(3):444-454. https://doi.org/10.1038/nn.3948

Fu Q-J, \& Shannon R V. (2000) Effect of stimulation rate on phoneme recognition by Nucleus22 cochlear implant listeners. J Acoust Soc Am 107(1):589-597. https://doi.org/10.1121/1.428325

Gjoni E, Zenke F, Bouhours B, \& Schneggenburger R (2018) Specific synaptic input strengths determine the computational properties of excitation-inhibition integration in a sound localization circuit. J Physiol 596(20):4945-4967. https://doi.org/10.1113/JP276012

Glasberg BR, \& Moore BCJ (1990) Derivation of auditory filter shapes from notched-noise data. Hear Res 47:103-138. https://doi.org/https://doi.org/10.1016/0378-5955(90)90170-T

Glendenning KK, Hutson KA, Nudo RJ, \& Masterton RB (1985) Acoustic chiasm II: Anatomical basis of binaurality in lateral superior olive of cat. J Comp Neurol 232(2):261-285. https://doi.org/10.1002/cne.902320210

Goldberg JM, \& Brown PB (1968) Functional organization of the dog superior olivary complex: an anatomical and electrophysiological study. J Neurophysiol 31(4):639-656. https://doi.org/10.1152/jn.1968.31.4.639

Goldberg JM, \& Brown PB (1969) Response of binaural neurons of dog superior olivary complex to dichotic tonal stimuli: some physiological mechanisms of sound localization. J Neurophysiol 32(4):613-636. https://doi.org/10.1152/jn.1969.32.4.613

Gransier R, Luke R, van Wieringen A, \& Wouters J (2020) Neural Modulation Transmission Is a Marker for Speech Perception in Noise in Cochlear Implant Users. Ear Hear 41(3):591602. https://doi.org/10.1097/AUD.0000000000000783

Grothe B, \& Sanes DH (1993) Bilateral inhibition by glycinergic afferents in the medial superior olive. J Neurophysiol 69(4):1192-1196. https://doi.org/10.1152/jn.1993.69.4.1192

Hodgkin AL, \& Huxley AF (1952) A quantitative description of ion currents and its applications to conduction and excitation in nerve membranes. J Physiol 117:500-544. https://doi.org/https://doi.org/10.1113/jphysiol.1952.sp004764

Hutcheon B, \& Yarom Y (2000) Resonance, oscillation and the intrinsic. Trends Neurosci 23(5):216-222. https://doi.org/10.1016/S0166-2236(00)01547-2

Joris PX (1996) Envelope coding in the lateral superior olive. II. Characteristic delays and comparison with responses in the medial superior olive. J Neurophysiol 76(4):2137-2156. https://doi.org/10.1152/jn.1996.76.4.2137

Joris PX, \& Yin TCT (1995) Envelope coding in the lateral superior olive. I. Sensitivity to interaural time differences. J Neurophysiol 73(3):1043-1062.

https://doi.org/10.1152/jn.1995.73.3.1043

Joris PX, \& Yin TCT (1998) Envelope coding in the lateral superior olive. III. Comparison with afferent pathways. J Neurophysiol 79(1):253-269. https://doi.org/10.1152/jn.1998.79.1.253 
Kan A, Goupell MJ, \& Litovsky RY (2019) Effect of channel separation and interaural mismatch on fusion and lateralization in normal-hearing and cochlear-implant listeners. J Acoust Soc Am 146(2):1448-1463. https://doi.org/10.1121/1.5123464

Kan A, Jones HG, \& Litovsky RY (2015) Effect of multi-electrode configuration on sensitivity to interaural timing differences in bilateral cochlear-implant users. J Acoust Soc Am 138(6):3826-3833. https://doi.org/10.1121/1.4937754

Kulesza RJ (2007) Cytoarchitecture of the human superior olivary complex: Medial and lateral superior olive. Hear Res 225(1-2):80-90. https://doi.org/10.1016/j.heares.2006.12.006

Laback B, Zimmermann I, Majdak P, Baumgartner W-D, \& Pok S-M (2011) Effects of envelope shape on interaural envelope delay sensitivity in acoustic and electric hearing. J Acoust Soc Am 130(3):1515-1529. https://doi.org/10.1121/1.3613704

Langendijk EHA, \& Bronkhorst AW (2002) Contribution of spectral cues to human sound localization. J Acoust Soc Am 112(4):1583-1596. https://doi.org/10.1121/1.1501901

Lorente De No R (1981) The Primary Acoustic Nuclei. New York: Raven.

Macpherson EA, \& Middlebrooks JC (2002) Listener weighting of cues for lateral angle: The duplex theory of sound localization revisited. J Acoust Soc Am 111(5):2219. https://doi.org/10.1121/1.1471898

Manis PB, \& Marx SO (1991) Outward currents in isolated ventral cochlear nucleus neurons. J Neurosci 11(9):2865-2880. https://doi.org/10.1523/JNEUROSCI.2541-12.2013

Mathews PJ, Jercog PE, Rinzel J, Scott LL, \& Golding NL (2010) Control of submillisecond synaptic timing in binaural coincidence detectors by Kv1 channels. Nat Neurosci 13(5):601-609. https://doi.org/10.1038/nn.2530

McFadden D, \& Pasanen EG (1976) Lateralization at high frequencies based on interaural time differences. J Acoust Soc Am 59(3):634-639. https://doi.org/10.1121/1.380913

Mills AW (1960) Lateralization of High $\square$ Frequency Tones. J Acoust Soc Am 32(1):132-134. https://doi.org/10.1121/1.1907864

Monaghan JJM, Bleeck S, \& McAlpine D (2015) Sensitivity to envelope interaural time differences at high modulation rates. Trends Hear 19:1-14. https://doi.org/10.1177/2331216515619331

Monaghan JJM, \& Seeber BU (2016) A method to enhance the use of interaural time differences for cochlear implants in reverberant environments. J Acoust Soc Am 140(2):1116-1129. https://doi.org/10.1121/1.4960572

Nilsson JW, \& Riedel SA (2008) Electric Circuits. Prentice Hall.

Plack CJ, Barker D, \& Prendergast G (2014) Perceptual consequences of "hidden" hearing loss. Trends Hear 18:1-11. https://doi.org/10.1177/2331216514550621

Puil E, Gimbarzevsky B, \& Miura RM (1986) Quantification of membrane properties of trigeminal root ganglion neurons in guinea pigs. J Neurophysiol 55(5):995-1016. https://doi.org/10.1152/jn.1986.55.5.995

Remme MWH, Donato R, Mikiel-Hunter J, Ballestero JA, Foster S, Rinzel J, \& McAlpine D 
(2014) Subthreshold resonance properties contribute to the efficient coding of auditory spatial cues. Proc Natl Acad Sci 111(22):E2339-E2348.

https://doi.org/10.1073/pnas.1316216111

Rothman JS, \& Manis PB (2003) The Roles Potassium Currents Play in Regulating the Electrical Activity of Ventral Cochlear Nucleus Neurons. J Neurophysiol 89(6):3097-3113. https://doi.org/10.1152/jn.00127.2002

Sandel TT, Teas DC, Feddersen WE, \& Jeffress LA (1955) Localization of Sound from Single and Paired Sources. J Acoust Soc Am 27(5):842-852. https://doi.org/10.1121/1.1908052

Schulz D, Goaillard J, \& Marder E (2006) Variable channel expression in identified single and electrically coupled neurons in different animals. Nat Neurosci 9:356-362. https://doi.org/https://doi.org/10.1038/nn1639

Scott LL, Mathews PJ, \& Golding NL (2010) Perisomatic Voltage-Gated Sodium Channels Actively Maintain Linear Synaptic Integration in Principal Neurons of the Medial Superior Olive. J Neurosci 30(6):2039-2050. https://doi.org/10.1523/JNEUROSCI.2385-09.2010

Shader MJ, Nguyen N, Cleary M, Hertzano R, Eisenman DJ, Anderson S, ... Goupell MJ (2020) Effect of Stimulation Rate on Speech Understanding in Older Cochlear-Implant Users. Ear Hear 41(3):640-651. https://doi.org/10.1097/AUD.0000000000000793

Shannon R V., Cruz RJ, \& Galvin JJ (2011) Effect of Stimulation Rate on Cochlear Implant Users' Phoneme, Word and Sentence Recognition in Quiet and in Noise. Audiol Neurotol 16(2):113-123. https://doi.org/10.1159/000315115

Smith PH, Joris PX, Carney LH, \& Yin TCT (1991) Projections of physiologically characterized globular bushy cell axons from the cochlear nucleus of the cat. J Comp Neurol 304(3):387407. https://doi.org/10.1002/cne.903040305

Smith PH, Joris PX, \& Yin TCT (1993) Projections of physiologically characterized spherical bushy cell axons from the cochlear nucleus of the cat: Evidence for delay lines to the medial superior olive. J Comp Neurol 331(2):245-260.

https://doi.org/10.1002/cne.903310208

Spirou GA, Rager J, \& Manis PB (2005) Convergence Of Auditory-Nerve Fiber Projections onto Globular Bushy Cells. Neuroscience 136:843-863.

Srinivasan S, Laback B, Majdak P, \& Arnolder C (2020) Improving Interaural Time Difference Sensitivity Using Short Inter-pulse Intervals with Amplitude-Modulated Pulse Trains in Bilateral Cochlear Implants. JARO - J Assoc Res Otolaryngol. https://doi.org/https://doi.org/10.1007/s10162-020-00743-6

Srinivasan S, Laback B, Majdak P, \& Delgutte B (2018) Introducing Short Interpulse Intervals in High-Rate Pulse Trains Enhances Binaural Timing Sensitivity in Electric Hearing. JARO - J Assoc Res Otolaryngol 19(3):301-315. https://doi.org/10.1007/s10162-018-0659-7

Stakhovskaya OA, \& Goupell MJ (2017) Lateralization of Interaural Level Differences with Multiple Electrode Stimulation in Bilateral Cochlear-Implant Listeners. Ear Hear 38(1):e22e38. https://doi.org/https://doi.org/10.1097/AUD.0000000000000360

Sterenborg JC, Pilati N, Sheridan CJ, Uchitel OD, Forsythe ID, \& Barnes-Davies M (2010) 
Lateral olivocochlear (LOC) neurons of the mouse LSO receive excitatory and inhibitory synaptic inputs with slower kinetics than LSO principal neurons. Hear Res 270:119-126. https://doi.org/10.1016/j.heares.2010.08.013

Stern RM, \& Shear GD (1996) Effects of distribution of internal delay. J Acoust Soc Am 100(4):2278-2288.

Stimberg M, Brette R, \& Goodman DFM (2019) Brian 2, an intuitive and efficient neural simulator. ELife 8:1-41. https://doi.org/10.7554/eLife.47314

Thompson SK, Von Kriegstein K, Deane-Pratt A, Marquardt T, Deichmann R, Griffiths TD, \& McAlpine D (2006) Representation of interaural time delay in the human auditory midbrain. Nat Neurosci 9(9):1096-1098. https://doi.org/10.1038/nn1755

Todd AE, Goupell MJ, \& Litovsky RY (2019) Binaural unmasking with temporal envelope and fine structure in listeners with cochlear implants. J Acoust Soc Am 145(5):2982-2993. https://doi.org/10.1121/1.5102158

van de Par S, \& Kohlrausch A (1997) A new approach to comparing binaural masking level differences at low and high frequencies. J Acoust Soc Am 101(3):1671-1680. https://doi.org/10.1121/1.418151

van Hoesel RJM, Böhm M, Pesch J, Vandali A, Battmer RD, \& Lenarz T (2008) Binaural speech unmasking and localization in noise with bilateral cochlear implants using envelope and fine-timing based strategies. J Acoust Soc Am 123(4):2249-2263. https://doi.org/10.1121/1.2875229

Veerman CC, Podliesna S, Tadros R, Lodder EM, Mengarelli I, De Jonge B, ... Bezzina CR (2017) The brugada syndrome susceptibility gene HEY2 modulates cardiac transmural ion channel patterning and electrical heterogeneity. Circ Res 121(5):537-548. https://doi.org/10.1161/CIRCRESAHA.117.310959

von Kriegstein K, Griffiths TD, Thompson SK, \& McAlpine D (2008) Responses to Interaural Time Delay in Human Cortex. J Neurophysiol 100(5):2712-2718. https://doi.org/10.1152/jn.90210.2008

Wang L, \& Colburn HS (2012) A modeling study of the responses of the lateral superior olive to ipsilateral sinusoidally amplitude-modulated tones. JARO - J Assoc Res Otolaryngol 13(2):249-267. https://doi.org/10.1007/s10162-011-0300-5

Wightman FL, \& Kistler DJ (1992) The dominant role of low-frequency inter aural time differences in sound localization. J Acoust Soc Am 91(3):1648-1661. https://doi.org/10.1121/1.402445

Yin TCT, \& Chan JCK (1990) Interaural time sensitivity in medial superior olive of cat. J Neurophysiol 64(2):465-488. https://doi.org/10.1152/jn.1990.64.2.465

Zilany MSA, Bruce IC, \& Carney LH (2014) Updated parameters and expanded simulation options for a model of the auditory periphery. J Acoust Soc Am 135(1):283-286.

https://doi.org/10.1121/1.4837815 